\title{
The Contribution of Changes in Adenylyl Cyclase Signaling System of the Brain and Myocardium to Etiology and Pathogenesis of Diabetes Mellitus
}

\author{
Alexander Olegovich Shpakov \\ Additional information is available at the end of the chapter \\ http://dx.doi.org/10.5772/intechopen.73661
}

\begin{abstract}
The functional changes in hormone-sensitive adenylyl cyclase (AC) signaling system of the central nervous system (CNS) and periphery play a crucial role in etiology and pathogenesis of diabetes mellitus (DM). The identification of these changes in AC signaling system and the abnormalities in AC signaling network are necessary for creation of the new strategies to treat and prevent diabetic pathology. In this chapter, our data and the results of other authors on the changes in hormone-sensitive adenylyl cyclase signaling system (ACSS) in the diabetic brain and heart and on their contribution to etiology and pathogenesis of DM and its complications, diabetic cardiomyopathy in particular, are presented and analyzed, and the promising approaches to treat DM and its complications, which are based on the restoration of AC signaling cascades and their functional interaction, are discussed.
\end{abstract}

Keywords: diabetes mellitus, adenylyl cyclase system, brain, myocardium, bromocriptine

\section{Introduction}

Diabetes mellitus (DM) is a major global health problem affecting more than 350 million people worldwide. It is one of the most severe metabolic disorders in humans characterized by hyperglycemia due to insulin deficiency or insulin resistance of target tissues. Insulin-dependent, type 1, and non-insulin-dependent, type 2, DM (DM1 and DM2) induce a large number of diseases in the nervous, cardiovascular, endocrine, and other systems, and these complications of DM are found in more than one-quarter of diabetic patients [1-4]. It is generally accepted that the changes in hormonal signaling systems in the CNS and periphery play a crucial role 
in etiology and pathogenesis of DM and its complications. For a long time, the main attention was focused on the signaling systems regulated by insulin, insulin-like growth factor-1, and leptin, whose functional activity is largely impaired in DM1 and DM2 [5-8]. Meanwhile, in recent years, numerous data in favor of the close relationship between the changes in G protein-coupled signaling systems and the pathogenesis of DM were obtained. These systems are regulated by a broad spectrum of hormonal agents, such as amino acids and their derivatives, peptide and glycoprotein hormones, and nucleotides, which bind specifically to G proteincoupled receptors (GPCRs) seven times penetrating the plasma membrane.

The central role among these systems belongs to adenylyl cyclase signaling system (ACSS), which is represented in all types of cells and tissues and is responsible for hormonal regulation of fundamental cellular processes. The ACSS has the following main components: (1) $\mathrm{G}$ protein-coupled receptor (GPCR) recognizing and specifically interacting with hormonal stimuli, (2) $\alpha \beta \gamma$-heterotrimeric $G$ protein of the stimulatory $\left(\mathrm{G}_{\mathrm{s}}\right)$ and inhibitory $\left(\mathrm{G}_{\mathrm{i}}\right)$ types, (3) the enzyme adenylyl cyclase (AC) catalyzing the formation of cyclic AMP (cAMP), and (4) cAMP-activated protein kinase (PKA) and cAMP-activated guanine nucleotide exchange factors (Epac1 and Epac2) that control the cAMP-dependent intracellular cascades and transcription factors. As the pathological changes in ACSS lead to dysfunctions in most organs and tissues, they are one of the causes of severe complications of DM such as diabetic cardiomyopathy, nephropathy, encephalopathy, and metabolic and endocrine disorders.

This chapter describes our data and the results of other authors on the changes and abnormalities in hormone-sensitive ACSS in the diabetic brain and heart and their contribution into etiology and pathogenesis of DM and its complications, diabetic cardiomyopathy in particular, and on the approaches to treat DM, which are based on the restoration of AC-signaling cascades and their functional interaction.

\section{The ACSS in the diabetic brain}

It is shown that in DM, the functional activity of cAMP-dependent signaling pathways regulated by dopamine (DA), serotonin, and melanocortin peptides in the brain and especially in its hypothalamic area is changed significantly. This triggers neurodegenerative processes in the CNS and affects the central regulation of energy homeostasis, inducing peripheral insulin resistance and abnormalities in the lipid and carbohydrate metabolism (Figure 1).

The brain DA controls locomotor activity, cognition, feeding behavior, and via central mechanisms regulates functions of the endocrine and cardiovascular systems. The DA stimulates AC activity via $G_{s}$ protein-coupled dopamine receptor of the type $1\left(D_{1} R\right)$ and inhibits hormone-stimulated $A C$ activity via $G_{i}$ protein-coupled $D_{2} R$. In the hypothalamus and brainstem of rats with the streptozotocin (STZ) model of DM1, the concentration of DA and the number of $\mathrm{DA}_{2} \mathrm{R}$ decreased significantly [9]. The hypothalamus and brainstem are involved in the control of glucose homeostasis and feeding behavior. In patients and experimental animals with DM2 and metabolic syndrome, the activity of brain $\mathrm{D}_{2}$-dopaminergic system also reduced, as illustrated by a decrease of dopamine level and $\mathrm{DA}_{2} \mathrm{R}$ expression $[9,10]$. 


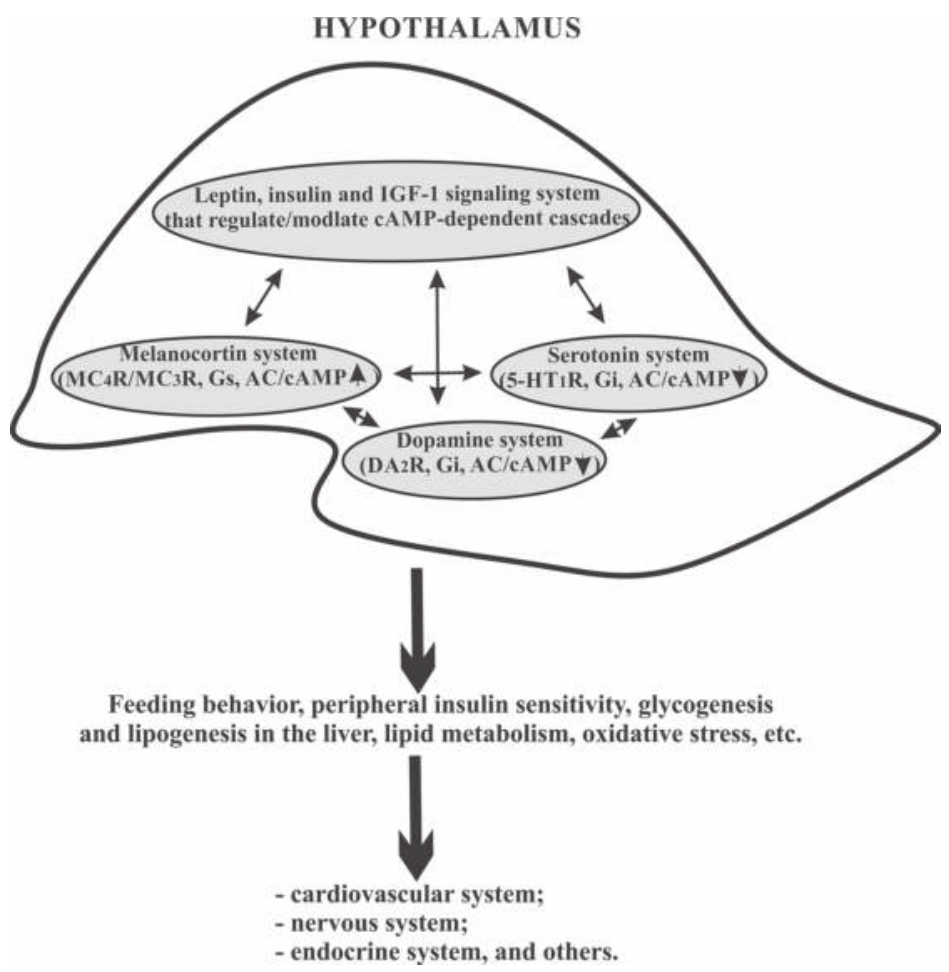

Figure 1. The interaction between hypothalamic signaling systems and their influence on the peripheral energy homeostasis and the functioning of organs and tissues.

We showed that in the brain and in the hypothalamus of rats with acute and moderate STZinduced DM1 and with neonatal and high fat diet (HFD)/STZ models of DM2, the inhibitory effect of $\mathrm{DA}_{2} \mathrm{R}$-agonists on forskolin-stimulated AC activity and on the expression of the Drd2 gene encoding $\mathrm{DA}_{2} \mathrm{R}$ was reduced significantly, especially in DM1 [11-14]. Meanwhile, the functional activity of $\mathrm{DA}_{1} \mathrm{R}$ pathway in the CNS of diabetic rats was changed to a small extent.

The restoration of brain $\mathrm{D}_{2}$-dopaminergic system in experimental and human DM2 can be achieved using the alkaloid bromocriptine $(B C)$, a selective $\mathrm{DA}_{2} \mathrm{R}$-agonist that activates $\mathrm{DA}_{2} \mathrm{R}$ and decreases intracellular cAMP level in neurons. In DM2, the BC inhibits the activity of hypothalamic neurons controlling glucose production and lipid synthesis in the liver, activates dopaminergic neurons regulating insulin sensitivity, and via central mechanisms improves functions of the cardiovascular system, preventing the development of severe forms of diabetic cardiomyopathy $[10,15,16]$. The effect of BC therapy on glucose homeostasis in DM2 is comparable to that of metformin, widely used antidiabetic drug, and, as demonstrated in clinical trials and in animal models, the co-administration of BC with metformin, glipizide, and pioglitazone enhances their glucose-lowering effect and reduces effective doses of these drugs, thereby preventing their adverse effects $[17,18]$. The glucose-lowering effect of glipizide when co-administered with BC is also increased in rats with the alloxan model of DM1 [19]. 
We demonstrated that 2-month BC treatment of rats with HFD-induced DM2 resulted in the improved glucose homeostasis and insulin sensitivity [20, 21]. The BC partially restored sensitivity of brain ACSS to agonists of 5-hydroxytryptamine receptors of the subtype $1 \mathrm{~B}\left(5-\mathrm{HT}_{1 \mathrm{~B}} \mathrm{R}\right)$ and somatostatin receptors, which indicates a functional relationship between $\mathrm{DA}_{2} \mathrm{R}$ signaling and the somatostatin and serotonin systems in the CNS [21]. The treatment of diabetic rats with $\mathrm{BC}$ also led to normalization of adrenergic signaling in the myocardium and to restoration of $\mathrm{AC}$ sensitivity to gonadotropin in testes, indicating a broad therapeutic potential of BC in DM2 [20].

Brain serotonin, acting on different types of 5-HTRs, regulates feeding behavior, motor activity, pain, depression, and learning. This neurotransmitter is also involved in the control of the cardiovascular, endocrine, and reproductive systems and in the regulation of production of insulin and other hormones by pancreatic islets [22]. It was shown that in patients with DM1 and DM2 and in animals with experimental models of DM1, the brain level of serotonin and its precursor tryptophan and the ratio of free-total tryptophan were significantly decreased. The decreased serotonin level and the changes in serotonin metabolism due to decrease in activity of tryptophan-5-hydroxylase-2, the rate-limiting enzyme in serotonin biosynthesis, led to impairment of serotonin signaling pathways in the brain and to alteration of the number and affinity of 5-HTRs, which weakens serotonin-mediated regulation of lipid and carbohydrate metabolism and insulin sensitivity [23, 24].

Based on serotonin deficiency in the diabetic brain, it can be assumed that increasing the serotonin level in CNS is an appropriate approach to normalize feeding behavior and improve glucose homeostasis and insulin sensitivity impaired in diabetic pathology. This suggestion is confirmed by the results obtained in treating diabetic patients with fluoxetine and other selective serotonin reuptake inhibitors. These inhibitors induced weight loss, reduced the plasma levels of glucose and glycated hemoglobin, and improved insulin sensitivity [25, 26].

We showed that long-term treatment of rats with neonatal and HFD/STZ DM2 using intranasally administered serotonin (IS) restored hormonal sensitivity of ACSS in the brain and in the periphery and improved metabolic parameters and cognitive functions [12, 13, 27]. The 8-week treatment of female rats with neonatal DM2 with IS $(20 \mu \mathrm{g} / \mathrm{rat}$ daily) restored AC-mediated regulatory effects of monoamines and relaxin in the brain, $\beta$-adrenergic agonists in the myocardium, and gonadotropins in ovaries [12, 28]. Along with it, using the Morris water test, we found that IS treatment improved DM-induced impairment of learning and spatial memory [12]. The 2-month IS treatment of male rats with HFD/low-dose STZ model of DM2 decreased the body weight, improved the glucose tolerance and insulin-induced glucose utilization, and also reduced the level of triglycerides and LDL-cholesterol, and the LDL/HDL-cholesterol ratio, which indicates the normalization of lipid metabolism. Besides, IS treatment restored hormonal sensitivity of ACSS in the hypothalamus and normalized the ratio of $\beta_{1}^{-}, \beta_{2}-$, and $\beta_{3}$-adrenergic receptors ( $\beta$-ARs) in the myocardium of diabetic rats. Based on these findings, we can conclude that increasing the brain serotonin level may be an effective way to treat DM2 and its complications that are induced by abnormalities in the brain and peripheral AC signaling [13].

The hypothalamic melanocortin system plays a very important role in regulation of feeding behavior, insulin sensitivity, and lipid metabolism [29]. The sensor components of this system are $G_{s}$ protein-coupled melanocortin receptors of the types 3 and $4\left(M C_{3} R\right.$ and $\left.M C_{4} R\right)$. They are activated by $\alpha$-melanocyte-stimulating hormone $(\alpha-\mathrm{MSH})$ and other peptides of 
the melanocortin family generated from pro-opiomelanocortin (POMC) that is produced by POMC-expressing neurons of the arcuate nucleus of hypothalamus. The binding of $\mathrm{MC}_{3} \mathrm{R}$ and $\mathrm{MC}_{4} \mathrm{R}$ with agonists leads to activation of $\mathrm{AC}$ and cAMP-dependent signaling cascades. Along with melanocortin peptides, the agouti-related peptide (AgRP) with $\mathrm{MC}_{4} \mathrm{R}$ antagonistic activity is produced in the arcuate nucleus, and it inhibits regulatory effects of $\alpha$-MSH and triggers $G$ protein-independent arrestin signaling [30].

The inhibition of $\mathrm{MC}_{4} \mathrm{R}$-signaling cascades led to hyperphagia, metabolic disorders, insulin resistance, and eventually to DM2 [31]. Mice lacking $\mathrm{MC}_{4} \mathrm{R}$ and agouti mice with increased AgRP expression had the reduced insulin sensitivity, and treatment of healthy mice by $\mathrm{MC}_{4} \mathrm{R}$ antagonists and high-dose AgRP enhanced appetite and induced insulin resistance [32, 33]. Some patients with DM2 and metabolic syndrome were characterized by mutations in the Mc4r gene and by impaired $\mathrm{MC}_{4} \mathrm{R}$ signaling [34]. The $\alpha-\mathrm{MSH}$ and other $\mathrm{MC}_{4} \mathrm{R}$ agonists, on the contrary, had an antidiabetic effect when administered to rodents with obesity and insulin resistance. They reduced food intake and normalized the glucose and insulin level and energy metabolism [31, 32].

We showed that in the hypothalamus of rats with neonatal and HFD/low-dose STZ DM2, the activity of $\mathrm{MC}_{4} \mathrm{R}$-signaling pathway decreased significantly. This was illustrated by decrease of the $M c 4 r$ gene expression and the stimulating effects of $\alpha$-MSH and selective $\mathrm{MC}_{4} \mathrm{R}$-agonist THIQ on AC activity and GTP-binding capacity of $\mathrm{G}_{\mathrm{s}}$ proteins. The long-term treatment of diabetic animals with $\mathrm{BC}$ and intranasally administered insulin and serotonin significantly restored $\mathrm{MC}_{4} \mathrm{R}$ signaling, and this coincided with the improvement of insulin sensitivity and the carbohydrate and lipid metabolism [13].

One of the approaches to restore hypothalamic melanocortin system in DM2 is the use of selective $\mathrm{MC}_{4} \mathrm{R}$-agonists, as demonstrated in the experiments with obese and diabetic animals. But currently, there are no available highly selective $\mathrm{MC}_{4} \mathrm{R}$-agonists, while melanotanII, the most widely used non-selective MCR agonist, leads to a large number of adverse effects [35]. Currently, new agonists of $\mathrm{MC}_{4} \mathrm{R}$ are being developed intensively, but they have not been used in clinic yet. The most effective among them are $\alpha$-MSH analogs modified by fatty acid radicals at the $\mathrm{N}$-terminus, highly selective $\mathrm{MC}_{4} \mathrm{R}$ agonist BIM-22493 [36, 37]. The BIM22493 easily penetrates across blood-brain barrier, activates hypothalamic $\mathrm{MC}_{4} \mathrm{R}$-signaling pathways, and, as a result, decreases food intake, body weight and fat mass, and improves glucose tolerance. It should be noted that even a long-term treatment of experimental animals with BIM-22493 had no adverse effects on the cardiovascular system and blood pressure [37]. The effectiveness of $\mathrm{MC}_{4} \mathrm{R}$ agonists can be significantly enhanced when they are combined with agonist of glucagon-like peptide- 1 receptor, which is widely used to treat DM2. Co-administration of BIM-22493 and liraglutide, a stable agonist of glucagon-like peptide-1 receptor, into diabetic mice prevented insulin resistance and improved energy expenditure much more effectively as compared to monotherapy [38].

\section{The ACSS in the diabetic heart}

The DM1 and DM2 are closely associated with severe cardiovascular diseases, such as acute myocardial infarction, congestive heart failure, and atherosclerosis [39, 40]. The pathological 
changes in contractile function of the heart in DM are largely due to impairment of the adrenergic, cholinergic, and purinergic pathways of AC regulation in cardiomyocytes [28, 39, 41-44]. The adrenergic signaling has a very important role in the functioning of the cardiovascular system, and it changes to the greatest extent in DM. In rats with the STZ model of DM1, the expression of genes encoding $\beta$-ARs and the activity of the receptors are altered and the pathological changes are enhanced with increasing duration and severity of DM [41]. In the cardiac muscle, there are three pharmacologically distinct subtypes of $\beta$-ARs. The $G_{s}$ protein-coupled $\beta_{1}-A R$ stimulates AC activity, $\beta_{2}$-AR interacts with the $G_{s}$ and $G_{i}$ proteins, and is able to both stimulate and inhibit AC activity, while $\beta_{3}$-AR interacts preferably with $G_{i}$ protein, inhibiting AC.

In diabetic rats with 6-14 week DM1, the expression of gene encoding $\beta_{1}$-AR was significantly reduced, while the expression of $\beta_{2}$-AR gene, on the contrary, was increased. The number of functionally active $\beta$-ARs on the surface of cardiomyocytes was reduced for both $\beta_{1}$ - and $\beta_{2}$-ARs, which is caused by increasing the rate of $\beta_{2}$-AR degradation and the deterioration of post-translational processing of receptor [41, 45]. Meanwhile, the mRNA level for $\beta_{3}$-AR and the number of these receptors on the surface of cardiomyocytes in rats with 14-weeks DM1 increased 2 or more times in comparison with control animals. The specificity of changes for $\beta$-AR subtypes in diabetic heart resulted in alteration of the $\beta_{1} /$ $\beta_{2} / \beta_{3}$ ratio. In the myocardium of diabetic rats, the ratio was $40: 36: 23$, while in the myocardium of healthy rats, the ratio was 62:30:8 [45]. The treatment of diabetic rats with insulin led to normalization of the $\beta_{1} / \beta_{2} / \beta_{3}$ ratio (57:33:10). The specific changes in $\beta$-AR activity including two or threefold increase in the number of $\beta_{3}$-AR were identified in the cardiac muscle of patients with DM2 and metabolic syndrome, as well as in patients with acute heart failure [46]. The study of genotype of patients with DM2 and metabolic syndrome allowed detecting the mutation in a codon 64 of $\beta_{3}$-AR gene, which led to a significant increase of activity of mutant receptor [47]. We also showed significant changes in the $\beta_{1} /$ $\beta_{2} / \beta_{3}$ ratio in the myocardium of rats with different models of diabetic pathology, and the ratio was restored when the animals were treated with intranasal insulin and, in the case of DM2, with $D_{2}$-agonist $B C$ and metformin $[13,20,28,44]$. The increase of $\beta_{3}$-AR activity prevents $A C$ hyperactivation caused by the increased catecholamine levels characteristic for diabetic cardiomyopathy. The increase of $\beta_{3}$-AR activity can also be a compensatory mechanism contributing to the preservation of functional activity of endothelial NO-synthase and soluble guanylyl cyclase that regulate vascular contractility [46]. However, with prolonged duration of DM, the increase of $\beta_{3}$-AR signaling in the myocardium leads to imbalance of adrenergic regulation and induces the negative inotropic effect of $\beta$-AR agonists and bradycardia [41].

The apoptotic processes in the cardiac muscle contribute significantly to etiology and pathogenesis of diabetic cardiomyopathy, and they largely depend on the $\beta_{1}$-AR signaling. A decrease in $\beta_{1}$-AR activity in the cardiac muscle in DM1 leads to inhibition of apoptotic processes in cardiomyocytes and prevents myocardial dysfunction and acute heart failure. It should be noted that in healthy animals, $\beta_{1}$-AR agonists induce apoptosis in rat cardiomyocytes, while $\beta_{1}$-AR antagonists suppress it [48].

We studied ACSS activity in the myocardium of rats with acute DM1 induced by high-dose STZ and found the decrease of the basal level of GTP-binding and the AC stimulating effect of 
guanine nucleotides, which indicates a weakening of $\mathrm{G}_{\mathrm{s}}$ protein function in cardiomyocytes of diabetic animals [49]. Meanwhile, the stimulation of AC by forskolin that directly interacts with catalytic site of the enzyme did not change, indicating the preservation of AC catalytic activity. The AC stimulating effect of $\beta$-agonists was decreased, but to a small extent, while the corresponding effect of relaxin, a peptide hormone that plays an important role in regulation of the cardiovascular system, was decreased by $48 \%$. The study of ACSS in the heart of rats with 7-month DM1 induced by multiple injections of low-dose STZ shows the decrease of both basal and forskolin/guanine nucleotides-stimulated AC activity, demonstrating the reduced activity of both $A C$ and $G_{s}$ protein [50]. A significant decrease in the norepinephrine and isoproterenol effects on AC activity, more pronounced than in acute DM1, was also observed. The changes of ACSS activity significantly depended on the age of rats when DM1 was initiated $[44,50]$. Our results indicate that changes in adrenergic signaling cascades in the heart are highly dependent on the experimental model of DM1.

Unlike DM1, in DM2, the number of $\beta$-ARs in the myocardium is not substantially different from control, but the sensitivity of $\beta$-ARs to agonists and their effects on AC are decreased significantly $[11,13,51-53]$. The changes in $\beta$-AR signaling strongly vary in rats with different models of DM2 depending on duration and severity of the disease [11, 44, 49, 53, 54]. In the myocardium of rats with 8-month neonatal model of DM2, the effect of isoproterenol on AC activity was increased, although to a small extent. When the duration of DM2 was 18 months, this effect was reduced as compared with the control group. The stimulating effect of relaxin on AC was reduced in DM2 with different durations, and in 18-months DM2, it did not exceed $46 \%$ of that in control [42]. The decrease of effect of guanine nucleotides on AC was shown, indicating a weakening of $G_{s}$ protein function, and one of the causes for this is hyperhomocysteinemia, typical for severe DM2 [54].

It was shown that the treatment of diabetic rats with thyroid hormone levothyroxine was effective for restoration of the number and functional activity of $\beta$-ARs [55, 56]. This indicates a close relationship between hypothyroid state, typical for human DM1 and DM2, and impaired myocardial function in DM. In this regard, there are serious grounds to believe that one of the approaches to prevent diabetic cardiomyopathy is restoration of hypothalamicpituitary-thyroid axis and compensation of thyroid hormones deficiency. The treatment of DM2 rats with $\mathrm{D}_{2}$-agonist $\mathrm{BC}$ and intranasally administered insulin and serotonin, restoring hypothalamic ACSS, also improves the function of the cardiovascular system and sensitivity of myocardial AC to hormonal regulators [20, 28].

\section{Concluding remarks}

Summing up, the changes in hormone-regulated ACSS in the brain and heart and abnormalities of interaction between them are the most important factors leading to the development of $\mathrm{DM}$ and its complications. Consequently, the identification of disturbances in these cascades and the development of approaches to their correction should be regarded as the most promising strategy to treat and prevent diabetic pathology. The causal link between DM and the pathological changes in AC signaling is not a one-way avenue, from DM to these changes in the 
organs and tissues and, further, to diabetic encephalopathy, cardiomyopathy, and other complications of DM. The opposite situation can also be realized when impaired AC signaling triggers the processes leading to DM. The dysfunctions in the brain ACSS sensitive to melanocortin peptides and monoamines can induce DM2 and metabolic syndrome, while dysregulation of cAMP signaling in the pancreatic islets weakens insulin-producing function of $\beta$-cells and provokes the development of DM1. This speaks in favor of the use of a wide scale of hormonal and non-hormonal agents that control AC activity and influence the availability, transport, and secretion of hormonal molecules in the treatment and prevention of DM. The development of new approaches for the treatment of DM, which are based on the monitoring and correction of the ACSS activity in the brain, myocardium, and the other organs and tissues, requires a detailed study of the changes in the ACSS in different forms of experimental and human $\mathrm{DM}$, as well as the effects on the ACSS of a number of the factors, such as the duration and severity of DM, the DM treatment with insulin, metformin, and other drugs, the frequency of hypoglycemic episodes, and the DM-induced complications. Nowadays, in our Laboratory of Molecular Endocrinology and Neurochemistry, Sechenov Institute of Evolutionary Physiology and Biochemistry, we use a lot of models of DM and various approaches of molecular endocrinology, pharmacology, and experimental medicine in order to understand etiology and pathogenesis of DM and its complications and to propose the new strategies to treat them.

\section{Acknowledgements}

This work was supported by the Russian Science Foundation (No 14-15-00413) (Section 2) and by the state assignment of FASO of Russia ("The mechanisms of development of neuropsychic, metabolic and hormonal dysfunctions in the nervous and endocrine diseases and the approaches for their correction") (Section 3).

\section{Author details}

Alexander Olegovich Shpakov

Address all correspondence to: alex_shpakov@list.ru

I.M. Sechenov Institute of Evolutionary Physiology and Biochemistry RAS, St. Petersburg, Russia

\section{References}

[1] Tabit CE, Chung WB, Hamburg NM, Vita JA. Endothelial dysfunction in diabetes mellitus: Molecular mechanisms and clinical implications. Reviews in Endocrine \& Metabolic Disorders. 2010;11:61-74. DOI: 10.1007/s11154-010-9134-4 
[2] Magge SN. Cardiovascular risk in children and adolescents with type 1 and type 2 diabetes mellitus. Current Cardiovascular Risk Reports. 2012;6:591-600. DOI: 10.1007/s121 70-012-0274-9

[3] Umegaki H, Hayashi T, Nomura H, Yanagawa M, Nonogaki Z, Nakshima H, et al. Cognitive dysfunction: An emerging concept of a new diabetic complication in the elderly. Geriatrics \& Gerontology International. 2013;13:28-34. DOI: 10.1111/j.1447-0594.2012. 00922.x

[4] Kahaly GJ, Hansen MP. Type 1 diabetes associated autoimmunity. Autoimmunity Reviews. 2016;15:644-648. DOI: 10.1016/j.autrev.2016.02.017

[5] Clemmons DR. Metabolic actions of insulin-like growth factor-I in normal physiology and diabetes. Endocrinology and Metabolism Clinics of North America. 2012;41:425-443. DOI: $10.1016 /$ j.ecl.2012.04.017

[6] Meek TH, Morton GJ. Leptin, diabetes, and the brain. Indian Journal of Endocrinology and Metabolism. 2012;16:534-542. DOI: 10.4103/2230-8210.105568

[7] Shpakov AO, Derkach KV, Berstein LM. Brain signaling systems in the type 2 diabetes and metabolic syndrome: Promising target to treat and prevent these diseases. Future Science OA (FSO). 2015;1:FSO25. DOI: 10.4155/fso.15.23

[8] Shpakov AO. The brain leptin signaling system and its functional state in metabolic syndrome and type 2 diabetes mellitus. Journal of Evolutionary Biochemistry and Physiology. 2016;52:177-195. DOI: 10.1134/S0022093016030017

[9] Shankar PN, Joseph A, Paulose CS. Decreased [ $\left.{ }^{3} \mathrm{H}\right]$ YM-09151-2 binding to dopamine D2 receptors in the hypothalamus, brainstem and pancreatic islets of streptozotocin-induced diabetic rats. European Journal of Pharmacology. 2007;557:99-105. DOI: 10.1016/j.ejphar. 2006.11.018

[10] Grunberger G. Novel therapies for the management of type 2 diabetes mellitus: Part 1. Pramlintide and bromocriptine-QR. Journal of Diabetes. 2013;5:110-117. DOI: 10.1111/ 1753-0407.12034

[11] Shpakov AO, Chistyakova OV, Derkach KV, Moiseyuk IV, Bondareva VM. Intranasal insulin affects adenylyl cyclase system in rat tissues in neonatal diabetes. Central European Journal of Biology. 2012;7:33-47. DOI: 10.2478/s11535-011-0089-6

[12] Shpakov AO, Derkach KV, Chistyakova OV, Sukhov IB, Shipilov VN, Bondareva VM. The brain adenylyl cyclase signaling system and cognitive functions in rat with neonatal diabetes under the influence of intranasal serotonin. Journal of Metabolic Syndrome. 2012;1:1000104. DOI: 10.4172/jms.1000104

[13] Derkach KV, Bondareva VM, Chistyakova OV, Berstein LM, Shpakov AO, The effect of long-term intranasal serotonin treatment on metabolic parameters and hormonal signaling in rats with high-fat diet/low-dose streptozotocin-induced type 2 diabetes. International Journal of Endocrinology. 2015;2015:245459. DOI: 10.1155/2015/245459 
[14] Sukhov IB, Derkach KV, Shpakov AO. Comparative study of functional activity of the D2-dopaminergic system in the hypothalamus of rats with different models of diabetes mellitus. Journal of Evolutionary Biochemistry and Physiology. 2016;52:267-269. DOI: 10.1134/S0022093016030108

[15] Scranton R, Cincotta A. Bromocriptine-Unique formulation of a dopamine agonist for the treatment of type 2 diabetes. Expert Opinion on Pharmacotherapy. 2010;11:269-279. DOI: $10.1517 / 14656560903501544$

[16] Weiland CM, Hilaire ML. Bromocriptine mesylate (Cycloset) for type 2 diabetes mellitus. American Family Physician. 2013;87:718-720 http://www.aafp.org/afp/steps

[17] Vinik AI, Cincotta AH, Scranton RE, Bohannon N, Ezrokhi M, Gaziano JM. Effect of bromocriptine-QR on glycemic control in subjects with uncontrolled hyperglycemia on one or two oral anti-diabetes agents. Endocrine Practice. 2012;18:931-943. DOI: 10.4158/ EP12187.OR

[18] Ghosh A, Sengupta N, Sahana P, Giri D, Sengupta P, Das N. Efficacy and safety of add on therapy of bromocriptine with metformin in Indian patients with type 2 diabetes mellitus: A randomized open labeled phase IV clinical trial. Indian Journal of Pharmacology. 2014;46:24-28. DOI: 10.4103/0253-7613.125160

[19] Kumar VSH, Vinutha MB, Aithal S, Baleed SR, Patil UN. Bromocriptine, a dopamine (d2) receptor agonist, used alone and in combination with glipizide in sub-therapeutic doses to ameliorate hyperglycaemia. Journal of Clinical and Diagnostic Research. 2013;7:19041907. DOI: $10.7860 / J C D R / 2013 / 5803.3347$

[20] Derkach KV, Bondareva VM, Moiseyuk IV, Shpakov AO. The effect of 2-month bromocriptine treatment on the activity of the adenylate cyclase signaling system in the myocardium and testes of rats with type 2 diabetes. Cell and Tissue Biology. 2015;9:395405. DOI: 10.1134/S1990519X15050041

[21] Shpakov AO, Derkach KV, Chistyakova OV, Bondareva VM. The influence of bromocryptine treatment on activity of the adenylyl cyclase system in the brain of rats with type 2 diabetes mellitus induced by high-fat diet. Doklady Biochemistry and Biophysics. 2014;459:186-189. DOI: 10.1134/S1607672914060027

[22] Barnes NM, Sharp T. A review of central 5-HT receptors and their function. Neuropharmacology. 1999;38:1083-1152. DOI: 10.1016/S0028-3908(99)00010-6

[23] Kloiber S, Kohli MA, Brueckl T, Ripke S, Ising M, Uhr M, et al. Variations in tryptophan hydroxylase 2 linked to decreased serotonergic activity are associated with elevated risk for metabolic syndrome in depression. Molecular Psychiatry. 2010;15:736-747. DOI: 10.1038/mp.2008.142

[24] Herrera-Marquez R, Hernandez-Rodriguez J, Medina-Serrano J, Boyzo-Montes de Oca A, Manjarrez-Gutierrez G. Association of metabolic syndrome with reduced central serotonergic activity. Metabolic Brain Disease. 2011;26:29-35. DOI: 10.1007/s11011-010-9229-3 
[25] Goodnick PJ. Use of antidepressants in treatment of comorbid diabetes mellitus and depression as well as in diabetic neuropathy. Annals of Clinical Psychiatry. 2001;13:31-41. PMID: 11465683

[26] Deuschle M. Effects of antidepressants on glucose metabolism and diabetes mellitus type 2 in adults. Current Opinion in Psychiatry. 2013;26:60-65. DOI: 10.1097/YCO.0b013 e32835a4206

[27] Sukhov IB, Derkach KV, Chistyakova OV, Bondareva VM, Shpakov AO. The effect of prolonged intranasal administration of serotonin on the activity of hypothalamic signaling systems in male rats with neonatal diabetes. Cell and Tissue Biology. 2016;10:314-323. DOI: 10.1134/S1990519X1604012X

[28] Shpakov AO, Derkach KV, Chistyakova OV, Moiseyuk IV, Sukhov IB, Bondareva VM. Effect of intranasal insulin and serotonin on functional activity of the adenylyl cyclase system in myocardium, ovary, and uterus of rats with prolonged neonatal model of diabetes mellitus. Journal of Evolutionary Biochemistry and Physiology. 2013;49:153-164. DOI: 10.1134/S0022093013020047

[29] Jeong JK, Kim JG, Lee BJ. Participation of the central melanocortin system in metabolic regulation and energy homeostasis. Cellular and Molecular Life Sciences. 2014;71:37993809. DOI: 10.1007/s00018-014-1650-z

[30] Bäckberg M, Madjid N, Ogren SO, Meister B. Down-regulated expression of agoutirelated protein (AGRP) mRNA in the hypothalamic arcuate nucleus of hyperphagic and obese tub/tub mice. Brain Research. Molecular Brain Research. 2004;125:129-139. DOI: 10.1016/j.molbrainres.2004.03.012

[31] Nogueiras R, Wiedmer P, Perez-Tilve D, Veyrat-Durebex C, Keogh JM, Sutton GM, et al. The central melanocortin system directly controls peripheral lipid metabolism. The Journal of Clinical Investigation. 2007;117:3475-3488. DOI: 10.1172/JCI31743

[32] Balthasar N, Dalgaard LT, Lee CE, Yu J, Funahashi H, Williams T, et al. Divergence of melanocortin pathways in the control of food intake and energy expenditure. Cell. 2005;123:493-505. DOI: 10.1016/j.cell.2005.08.035

[33] Haskell-Luevano C, Schaub JW, Andreasen A, Haskell KR, Moore MC, Koerper LM, et al. Voluntary exercise prevents the obese and diabetic metabolic syndrome of the melanocortin-4 receptor knockout mouse. The FASEB Journal. 2009;23:642-655. DOI: 10.1096/ fj.08-109686

[34] Pan Q, Delahanty LM, Jablonski KA, Knowler WC, Kahn SE, Florez JC, et al. Variation at the melanocortin 4 receptor gene and response to weight-loss interventions in the diabetes prevention program. Obesity (Silver Spring). 2013;21:520-526. DOI: 10.1002/oby.20459

[35] Wikberg JE, Mutulis F. Targeting melanocortin receptors: An approach to treat weight disorders and sexual dysfunction. Nature Reviews. Drug Discovery. 2008;7:307-323. DOI: $10.1038 /$ nrd2331 
[36] Conde-Frieboes K, Thøgersen H, Lau JF, Sensfuss U, Hansen TK, Christensen L, et al. Identification and in vivo and in vitro characterization of long acting and melanocortin 4 receptor (MC4-R) selective $\alpha$-melanocyte-stimulating hormone $(\alpha-\mathrm{MSH})$ analogues. Journal of Medicinal Chemistry. 2012;55:1969-1977. DOI: 10.1021/jm201489a

[37] Kievit P, Halem H, Marks DL, Dong JZ, Glavas MM, Sinnayah P, et al. Chronic treatment with a melanocortin-4 receptor agonist causes weight loss, reduces insulin resistance, and improves cardiovascular function in diet-induced obese rhesus macaques. Diabetes. 2013;62:490-497. DOI: 10.2337/db12-0598

[38] Clemmensen C, Finan B, Fischer K, Tom RZ, Legutko B, Sehrer L, et al. Dual melanocortin-4 receptor and GLP-1 receptor agonism amplifies metabolic benefits in diet-induced obese mice. EMBO Molecular Medicine. 2015;7:288-298. DOI: 10.15252/emmm.201404508

[39] Altan VM, Arioglu E, Guner S, Ozcelikay AT. The influence of diabetes on cardiac $\beta$-adrenoceptor subtypes. Heart Failure Reviews. 2007;12:58-65. DOI: 10.1007/s10741-0079005-6

[40] Chavali V, Tyagi SC, Mishra PK. Predictors and prevention of diabetic cardiomyopathy. Diabetes, Metabolic Syndrome and Obesity. 2013;6:151-160. DOI: 10.2147/DMSO.S3096

[41] Dincer UD, Bidasee KR, Guner S, Tay A, Ozçelikay AT, Altan VM. The effect of diabetes on expression of $\beta 1-, \beta 2$ - and $\beta 3$-adrenoreceptors in rat hearts. Diabetes. 2001;50:455-461. DOI: $10.2337 /$ diabetes.50.2.455

[42] Derkach KV, Shpakov AO, Moyseyuk IV, Chistyakova OV. The functional activity of adenylyl cyclase signaling system in the brain, myocardium, and testes of rats with 8and 18-month neonatal diabetes. Doklady Biochemistry and Biophysics. 2013;448:43-45. DOI: $10.1134 / S 1607672913010122$

[43] Shpakov AO, Derkach KV. The functional state of hormone-sensitive adenylyl cyclase signaling system in diabetes mellitus. Journal of Signal Transduction. 2013;2013:594213. DOI: $10.1155 / 2013 / 594213$

[44] Shpakov AO, Derkach KV, Chistyakova OV, Moyseyk IV, Bondareva VM. The effect of long-term diabetes mellitus induced by treatment with streptozotocin in 6-week-old rats on functional activity of the adenylyl cyclase system. Cell and Tissue Biology. 2014;8:6879. DOI: 10.1134/S1990519X14010118

[45] Matsuda N, Hattori Y, Gando S, Akaishi Y, Kemmotsu O, Kanno M. Diabetes-induced down-regulation of $\beta 1-A R$ mRNA expression in rat heart. Biochemical Pharmacology. 1999;58:881-885. DOI: 10.1016/S0006-2952(99)00164-1

[46] Rozec B, Gauthier C. $\beta_{3}$-Adrenoceptors in the cardiovascular system: Putative roles in human pathologies. Pharmacology \& Therapeutics. 2006;111:652-673. DOI: 10.1016/j. pharmthera.2005.12.002

[47] Sakane N, Yoshida T, Yoshioka K, Nakamura Y, Umekawa T, Kogure A, et al. Trp ${ }^{64}$ Arg mutation of $\beta_{3}$-adrenoceptor gene is associated with diabetic nephropathy in type II diabetes mellitus. Diabetologia. 1998;41:1533-1534. PMID: 9867224 
[48] Communal C, Singh K, Sawyer DB, Colucci WS. Opposing effects of $\beta 1$ - and $\beta 2$-adrenergic receptors on cardiac myocyte apoptosis. Role of pertussis-toxin sensitive G protein. Circulation. 1999;100:2210-2212. DOI: 10.1161/01.CIR.100.22.2210

[49] Shpakov AO, Kuznetsova LA, Plesneva SA, Pertseva MN. Molecular mechanisms of modified sensitivity of the adenylate cyclase signaling system to biogenic amines during streptozotocin-induced diabetes. Bulletin of Experimental Biology and Medicine. 2005;140:304-308. DOI: 10.1007/s10517-005-0474-0

[50] Shpakov AO, Derkach KV, Moyseyuk IV, Chistyakova OV. Alterations of hormonesensitive adenylyl cyclase system in the tissues of rats with long-term streptozotocin diabetes and the influence of intranasal insulin. Dataset Papers in Pharmacology. 2013;2013:698435. DOI: 10.7167/2013/698435

[51] Banyasz T, Kalapos I, Kelemen SZ, Kovacs T. Changes in cardiac contractility in IDDM and NIDDM diabetic rats. General Physiology and Biophysics. 1996;15:357-369. PMID: 9228518

[52] Huisamen B, Marais E, Genade S, Lochner A. Serial changes in the myocardial betaadrenergic signalling system in two models of non-insulin dependent diabetes mellitus. Molecular and Cellular Biochemistry. 2001;219:73-82. PMID: 11354257

[53] Shpakov AO, Kuznetsova LA, Plesneva SA, Pertseva MN. Disturbance of transduction of adenylyl cyclase-inhibiting hormonal signaling in the myocardium and brain of rats with experimental type 2 diabetes. Cell and Tissue Biology. 2007;1:343-351. DOI: 10.1134/S1990519X07040062

[54] Mishra PK, Awe O, Metreveli N, Qipshidze N, Joshua IG, Tyagi SC. Exercise mitigates homocysteine- $\beta_{2}$-adrenergic receptor interactions to ameliorate contractile dysfunction in diabetes. International Journal of Physiology, Pathophysiology and Pharmacology. 2011;3:97-106. PMID: 21760968

[55] Sundaresan PR, Sharma VK, Gingold SI, Banerjee SP. Decreased $\beta$-adrenergic receptors in rat heart in streptozotocin-induced diabetes: Role of thyroid hormones. Endocrinology. 1984;114:1358-1363. DOI: 10.1210/endo-114-4-1358

[56] Derkach KV, Kuznetsova LA, Chistyakova OV, Ignatieva PA, Shpakov AO. The effect of four-week levothyroxine treatment on hormonal regulation of adenylyl cyclase in the brain and peripheral tissues of obese rats. Biochemistry (Moscow) Suppl Ser A: Membrane Cell Biol. 2015;9:236-245. DOI: 10.1134/S1990747815040030 
